\title{
Las deportistas olímpicas en los libros de texto de educación física: ¿presencia o ausencia de referentes en nuestro alumnado? \\ Olympic athletes in physical education textbooks: presence or absence of references in our students? \\ Sergio Ruiz-Rabadán, Irene Moya-Mata \\ Universidad de Valencia (España)
}

Resumen. La representación de las mujeres deportistas en los libros de texto de Educación Física supone un modelo de referencia a imitar por parte del alumnado; además de visibilizar por un lado a las deportistas dedicadas a la alta competición, y por otro, el deporte minoritario. El objetivo de este estudio es analizar la presencia de las deportistas olímpicas que se representan en los libros de texto de Educación Física en la etapa de Primaria, determinando su visibilización o invisibilización en dichos materiales curriculares. La muestra estuvo formada por seis libros de texto de la editorial Edelvives, la cual aborda el movimiento olímpico explícitamente. Se ha realizado un análisis cuantitativo y cualitativo, tanto de las imágenes como del texto, para medir la presencia y recurrencia de las mujeres. La técnica utilizada ha sido el análisis de contenido basado en un sistema de codificación ad hoc. Para el análisis estadístico se ha utilizado el programa estadístico informático SPSS 22.0. Los resultados muestran una infrarrepresentación de las deportistas olímpicas, siendo más presente el sexismo en el texto que en las imágenes. Estas mujeres deportistas son principalmente estadounidenses, sin discapacidad, que compiten en los Juegos Olímpicos de verano, en modalidades deportivas individuales, siendo el deporte por excelencia el atletismo, y la deportista olímpica con más presencia en estos manuales Nadia Comaneci. Es necesario que las editoriales revisen estos manuales y aumenten la presencia de mujeres deportistas, para ofrecer modelos femeninos como referentes en el alumnado de Primaria.

Palabras clave: mujer, referente deportivo, sexismo, Juegos Olímpicos, libros de texto, Educación Física, Educación Primaria.

Abstract. The representation of women athletes in Physical Education textbooks is a reference model that students may imitate, in addition to the fact that it makes visible on one hand female athletes from high competition, on the other hand minority sports. The objective of this study is to analyze the presence of Olympic athletes in the textbooks of Physical Education; determining their visibility or absence in said curricular materials. The sample consisted of six textbooks from the Edelvives publishing house, which explicitly addresses the Olympic movement. A quantitative and qualitative analysis was performed, both on the images and on the text, to measure the presence and recurrence of women references. Content analysis, based on an ad hoc coding system, was the technique employed. For the statistical analysis, the statistical software SPSS 22.0 was used. The results show a scarce presence of Olympic athletes in the manuals, being sexism more present in the text than in the images. These female athletes are mainly representative of the United States of America, without disabilities, competing in the Summer Olympic Games, in individual sports modalities, being the sport par excellence Athletics. The Olympic athlete most referred to in these manuals is Nadia Comaneci. It is necessary for publishers to review these manuals and increase the presence of female athletes, so to offer female models as referents in primary school students.

Keywords: woman, sport reference, sexism, Olympic Games, textbooks, Physical Education, Primary School.

\section{Introducción}

Los Juegos Olímpicos tienen su origen en los Antiguos Juegos celebrados cada cuatro años en la antigua Grecia. Sin embargo, estos dejaron de celebrarse en el año 393 d.C., momento en el que el emperador romano Teodosio prohibió cualquier manifestación pagana, entre ellas, el culto a los doce dioses olímpicos.

En sus orígenes las Olimpiadas estaban reservadas exclusivamente a los varones, por lo que las mujeres tenían prohibido tanto el acceso como la participación en los eventos deportivos. Este veto se mantuvo en la reinstauración de los Juegos Olímpicos (JJOO) Modernos en el año 1896, con Pierre de Coubertin, argumentando que la presencia de una mujer en un estadio resultaba antiestética e incorrecta y que su papel debía limitarse a aplaudir a los atletas masculinos (Jiménez, 2015).

A pesar del veto inicial, en los JJOO de París en 1900 participaron por primera vez 22 deportistas femeninas, es decir, un $2.2 \%$ del total de deportistas. En cambio, la primera aparición de las deportistas femeninas en los JJOO de invier-

Fecha recepción: 22-10-19. Fecha de aceptación: 15-01-20 Irene Moya-Mata irene.moya@uv.es no no tuvo lugar hasta 1924 en la localidad francesa de Charmonix, con 11 mujeres; lo que supone un $4.3 \%$ del total de participantes. (International Olympic Committee, 2018).

Actualmente, según datos facilitados por el Comité Olímpico Internacional (COI), la presencia femenina en los eventos olímpicos ha ido aumentando. Muestra de ello son los últimos JJOO de inviernos celebrados en Pieonchang (2018), donde la participación femenina ha representado un $43 \% \mathrm{del}$ total. Asimismo, en la última cita olímpica estival celebrada en Río de Janeiro en 2016, el porcentaje de mujeres participantes superó el $45 \%$. Estos datos son un claro reflejo de la evolución del olimpismo femenino.

No obstante, a pesar de que estos datos muestran una clara tendencia a la equiparación de participación femenina y masculina en las citas olímpicas, la representación de las mujeres deportistas en los medios de comunicación españoles sigue siendo escasa (Angulo, 2007; ASPIC-Comunicación, 2013; Gómez-Colell, 2015, Gómez-Colell, Medina-Bravo, \& Ramón, 2017). Por lo tanto, la imagen de los diversos deportes que llega a los centros educativos y hogares está protagonizada mayoritariamente por deportistas masculinos; y esto provoca la falta de información y la ausencia de referentes deportivos femeninos (Ibáñez, 2001).

Aunque estudios recientes afirman que existe una mayor visibilización de la mujer en las noticias, ésta se muestra 
con un perfil todavía estereotipado; reproduciendo, por lo tanto, un mayor número de estereotipos de género (Gallur, \& García, 2019). Por lo que la situación no ha variado en las últimas décadas y el papel otorgado al deporte femenino en los medios de comunicación continúa siendo en muchas ocasiones meramente testimonial. Sainz de Baranda (2014) constata que únicamente en el 5.1\% de las noticias aparece una mujer como protagonista, y en el $2.9 \%$ de estos casos aparece acompañada de al menos un protagonista masculino. En esta línea, Gómez-Colell et al. (2017) corroboran que únicamente en el $12 \%$ de las portadas de los principales diarios deportivos españoles se hace referencia al deporte femenino.

Tras comprobar la escasa presencia de la mujer en los medios de comunicación deportivos, nos preguntamos si esta desigualdad se reproduce en los libros de texto. En este sentido, la Ley Orgánica 8/2013 para la Mejora de la Calidad Educativa (más conocida como LOMCE) pone de manifiesto una educación inclusiva y no sexista, que fomente la igualdad de derechos y oportunidades entre hombres y mujeres, sin discriminación de las personas con discapacidad, en el sistema educativo español.

Y es que el libro de texto, según Braga y Belver (2014), «(...) selecciona y representa el universo científico y cultural que se pretende enseñar a los estudiantes reflejando los valores, estereotipos e ideologías de una determinada sociedad» (p. 204).

En el área de Educación Física (EF), el estudio de MoyaMata y Ros (2018) muestra que sólo el 31.7\% de las imágenes que representan a deportistas de élite en los manuales de Primaria son mujeres. Y en la etapa de Secundaria, Sánchez, Martos-García y López (2017) analizan la presencia y recurrencia de las mujeres y los hombres deportistas en los libros de texto de $3^{\circ}$ y $4^{\circ}$ de dos editoriales, encontrando la ausencia de mujeres deportistas en la editorial Serbal y la presencia sólo del $15 \%$ en la editorial Teide. Es de destacar que en ambas editoriales que no existe casi recurrencia, es decir, los deportistas suelen aparecer sólo una vez. Por lo que una vez más, se confirma la ausencia de referentes deportivos femeninos en la etapa educativa obligatoria, de los seis a los 16 años.

Este trato desigual de imágenes masculinas y femeninas en los manuales de EF es constatado en diversos estudios, tanto en la etapa de Primaria como de Secundaria, donde se refleja un predominio de la imagen masculina frente a la femenina realizando actividad física y/o deportiva. No sólo en las imágenes que aparecen en el interior de los libros de texto (González-Palomares, Táboas-Pais, \& Rey-Cao, 2017; LópezNavajas, 2014; Moya-Mata, Ruiz-Sanchis, Martín, \& Ros, 2019; Táboas-Pais, \& Rey-Cao, 2012a;), sino también en las portadas de dichos manuales (Moya-Mata, Ruiz, \& Ros, 2017; Moya-Mata, Ros, \& Peirats, 2018), y en las imágenes relacionadas con la discapacidad (Martínez-Bello, \& Molina-García, 2016; Moya-Mata, Ruiz, Martín, Pérez, \& Ros, 2017; TáboasPais, \& Rey-Cao, 2012b). Entre las pautas que Lleixà, Soler y Serra (2020) recomiendan para fomentar unas prácticas educativas desde una perspectiva de género, se encuentra la elaboración y el uso de materiales didácticos que adopten esta perspectiva.

Según Meier (2015), la ausencia de modelos deportivos femeninos retroalimenta la percepción común en los y las estudiantes de que los niños son mejores en el deporte que las niñas, dado que las chicas tienen menos acceso al deporte y, por lo tanto, realizan menos actividad física. Por ello, las adolescentes necesitan referentes de atletas femeninas fuertes, seguras y sanas, que alienten a las niñas a practicar deporte y adquirir hábitos de vida saludables (Olmstead, 2015).

En las últimas décadas, con la evolución de los roles de géneros en nuestra sociedad, la presencia de la mujer en aquellos deportes tradicionalmente vinculados a hombres ha aumentado considerablemente, desafiando de este modo los estereotipos en su contra. Muestra de ello es el récord mundial de asistencia a un partido femenino registrado el 17 de marzo, entre el Atlético de Madrid féminas y el FC Barcelona femenino; logrando reunir en el estadio Wanda Metropolitano a un total de 60.739 personas (La Vanguardia, 2019). De este modo, las atletas de hoy son deportistas poderosas, tanto emocional como físicamente, que pueden servir de modelo para los más jóvenes (Chinurum, Ogunjlmi, \& O’Neill, 2014).

Por lo tanto, el objetivo del presente estudio es analizar los referentes deportivos olímpicos que se representan en los manuales de EF en la etapa de Primaria, con el fin de averiguar si éstos perpetúan modelos deportivos masculinos; o por el contrario visibilizan modelos deportivos femeninos, como referentes de nuestros adolescentes. Para ello observaremos la presencia y la recurrencia de los y las deportistas en estos libros de texto, para comprobar la importancia que se le otorga a cada uno de los sexos.

\section{Metodología}

\section{Diseño del estudio}

Esta investigación tiene un carácter cuantitativo, adoptando un estudio ex post facto, analizando las frecuencias y porcentajes de los hombres y mujeres deportistas olímpicos/as que aparecen en los manuales. Asimismo, se complementa con un análisis cualitativo a partir de las variables posteriormente señaladas que tiene como objetivo identificar la presencia o ausencia de estereotipos de género.

La técnica utilizada ha sido el análisis de contenido, mediante la lectura y observación sistemática de los manuales de texto, basándonos en estudios precedentes (López-Navajas, 2014; Moya-Mata, \& Ros, 2018; Sánchez et al., 2017).

\section{Muestra}

La muestra se compone de seis libros de texto de la editorial Edelvives. Los criterios de inclusión para la elección de la muestra fueron: pertenecer al área de EF, estar destinados al alumnado de EP, en lengua castellana, editados a partir de la LOE y certificados con el sello del Comité Olímpico Español (COE); siendo la editorial Edelvives la única que cumplía con todos los criterios (Tabla 1).

\begin{tabular}{lllc}
$\begin{array}{l}\text { Tabla } 1 \\
\text { Características de la muestra }\end{array}$ & & \\
\hline Cursos & \multicolumn{1}{c}{ Autores } & \multicolumn{1}{c}{ Título } & $\begin{array}{c}\text { Año } \\
\text { publicación }\end{array}$ \\
\hline & & & 2011 \\
Primero & Torrescusa, C. y Coterón, F.J. & Educación Física. 1 Primaria & 2011 \\
Segundo & Torrescusa, C. y Coterón, F.J. & Educación Física. 2 Primaria & 2012 \\
Tercero & Torrescusa, C. y Coterón, F.J. & Educación Física. 3 Primaria & 2012 \\
Cuarto & Torrescusa, C. y Coterón, F.J. & Educación Física. 4 Primaria & 2012 \\
Quinto & Torrescusa, C. y Coterón, F.J. & Educación Física. 5 Primaria & 2013 \\
Sexto & Torrescusa, C. y Coterón, F.J. & Educación Física. 6 Primaria & 2013 \\
\hline Fuente: elaboración propia. & & \\
\end{tabular}




\section{Variables}

Para analizar la presencia (p) y recurrencia (r) de los y las deportistas en los libros de texto de EF se ha seguido el procedimiento de Sánchez et al. (2017), en donde para la presencia (p) se ha contado la primera vez que aparecen las mujeres y hombres con nombre propio, y para la recurrencia (r) se ha contado todas las veces que se mencionan dichos deportistas.

Para analizar a las deportistas referenciadas se han seleccionado las variables: tipo de referencia, sexo, nacionalidad, discapacidad, tipo de deporte olímpico, clasificación deportiva y evento deportivo. Se tomó como variable independiente el sexo.

\section{Instrumento}

El instrumento utilizado para el análisis de la muestra parte del sistema de categorías diseñado por Moya-Mata y Ros (2018), en un estudio anterior, en el que analizan las imágenes de las deportistas femeninas en los libros de texto de EF (tabla 2).

\begin{tabular}{|c|c|c|}
\hline Dimensión & Categorías & Indicadores \\
\hline $\begin{array}{l}\text { Características } \\
\text { Técnicas }\end{array}$ & Tipo de referencia & $\begin{array}{l}\text { Textual } \\
\text { Imagen } \\
\text { Textual e imagen }\end{array}$ \\
\hline \multirow{3}{*}{$\begin{array}{l}\text { Características } \\
\text { del/de la deportista }\end{array}$} & Sexo & $\begin{array}{l}\text { Hombre } \\
\text { Mujer }\end{array}$ \\
\hline & Nacionalidad & $\begin{array}{l}\text { Tantas como existentes } \\
\text { en la muestra }\end{array}$ \\
\hline & Discapacidad & $\begin{array}{l}\text { Sin discapacidad } \\
\text { Con discapacidad }\end{array}$ \\
\hline \multirow{3}{*}{$\begin{array}{l}\text { Características del } \\
\text { Deporte }\end{array}$} & Tipo de deporte & $\begin{array}{l}\text { Tantos como existentes } \\
\text { en la muestra }\end{array}$ \\
\hline & Clasificación deportiva & $\begin{array}{l}\text { Individual } \\
\text { Colectivo } \\
\text { Ambos }\end{array}$ \\
\hline & Evento deportivo & $\begin{array}{lll}\text { Juegos } & \text { Olímpicos } & \text { de } \\
\text { Verano } & & \\
\text { Juegos Olímpicos } & \text { de } \\
\text { Invierno } & \\
\text { Juegos Paralímpicos }\end{array}$ \\
\hline
\end{tabular}

El sistema de categorías consta de tres dimensiones: características técnicas, características del/a deportista y características del deporte. En la dimensión relacionada con las características técnicas se incluye la categoría (a) tipo de referencia, que establece la forma en la que es referenciada la o el deportista en el libro de texto: textual, imagen y textual e imagen.

En la dimensión características del/a deportista se incluyen las categorías: (a) sexo, condición que establece diferencias biológicas entre hombres y mujeres: hombre y mujer, (b) nacionalidad, condición que reconoce a una persona la pertenencia a un estado o nación: tantas como existentes en la muestra y, por último, (c) discapacidad, en función de la presencia o ausencia de limitación física, mental o sensorial: con discapacidad y sin discapacidad.

Y la dimensión características del deporte se corresponde con el deporte representado o mencionado en los libros de texto de EF practicado en unas olimpiadas o paralimpiadas, definida por categorías como: (a) tipo de deporte, en función del deporte practicado por la o el deportista: tantos como existentes en la muestra, (b) clasificación deportiva, categorización del deporte en función de si se realiza individualmente, en grupo o con oponente: individual, colectivo y ambos, y (c) evento deportivo, competición mundial donde participan los deportistas cada cuatro años: JJOO de verano, JJOO de invierno y JJPP.

\section{Procedimiento}

Para el análisis de las imágenes se han seleccionado aquéllas en donde aparecía una figura femenina y/o masculina en un contexto deportivo olímpico. Se han desechado las imágenes en las que no se reconocía el sexo del deportista, así como el resto de las imágenes que no tenían relación con la muestra de estudio. Y para el análisis del texto se ha realizado el mismo procedimiento, eliminando el nombre de aquellas personas que no se relacionaban con la muestra por no ser deportistas.

A continuación, se han seleccionado las imágenes y el texto asociado a las deportistas femeninas y se ha realizado un análisis cualitativo, a la vez que cuantitativo analizado su prevalencia, para averiguar qué modelos deportivos olímpicos femeninos y los deportes en los que participan se ofrecen al alumnado de Primaria en los manuales de EF.

\section{Análisis estadístico}

Para el tratamiento de los datos se ha utilizado el programa Statistical Package for Social Sciences (SPSS $®$ Inc, versión 21.0, Chicago, IL, USA) para Windows. Se realizó un análisis descriptivo univariable y los resultados se presentaron en porcentajes.

\section{Resultados}

La representación de los y las deportistas olímpicos en los libros de texto se ha medido cuantificando las referencias textuales halladas, independientemente de que se acompañen de una imagen o no. Así pues, la presencia de deportistas masculinos en los libros de texto de EF en la etapa de Primaria es del $72.2 \%$ y la recurrencia del $73.1 \%$. En cambio, las deportistas olímpicas se presentan en un $27.8 \%$ del total, con una recurrencia del 26.9\% (Tabla 3 ).

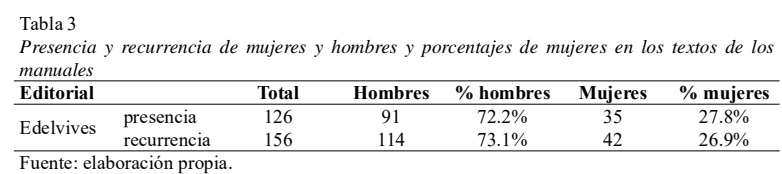

Este resultado también se manifiesta en el diferente tratamiento de éstos, como referentes deportivos; ya que al haber mayor presencia de hombres, los manuales analizados ofrecen más modelos deportivos masculinos de referencia al alumnado de EP(Tabla 4).

Concretamente, los referentes deportivos masculinos predominan en todos los cursos analizados, siendo $4^{\circ}$ de EP donde mayor porcentaje presenta $-25.6 \%$; ; al igual que las referentes femeninas olímpicas, aunque con un porcentaje mucho menor -10.8\%-, y sólo 17 referencias (figura 1).

Con respecto al análisis cualitativo de las referentes deportivas femeninas es de destacar que la nacionalidad más representada entre las olímpicas es la estadounidense, con un $21.4 \%$, seguida de la alemana con un $11.9 \%$; mientras que la nacionalidad española y rumana se representan con un 9.5\%. Cabe señalar que a lo largo de los libros analizados se mencionan deportistas de 35 nacionalidades diferentes, no obstante, para facilitar la comprensión de los datos se han agrupado en la variable «otros», aquéllas que representan un porcentaje menor al 5\%. A su vez, las referentes femeninas que aparecen en estos manuales no presentan ningún 
Tabla 4

Listado de deportistas mencionados y mencionadas en los manuales de EF en EP de la editorial Edelvives

\begin{tabular}{|c|c|c|c|c|}
\hline \multicolumn{3}{|c|}{ HOMBRES } & \multicolumn{2}{|c|}{ MUJERES } \\
\hline Adebe Bikila & Gervasio Deferr & Mike Powell & Andersen Scheiss & Kristin Otto \\
\hline Adhemar & Haile & Miklos Németh & Betty Cuthbert & Larisa Latynina \\
\hline Ferreira & Gebresalassie & Mitsuo & Birgit Fischer & Luigina Giavotti \\
\hline Akio Kaminaga & Hans-Gunnar & Tsukahara & Cathy Freeman & María Vasco \\
\hline Al Oerter & Liljenval & Nayoa Tsukahara & Chieko Oda & Marie-José \\
\hline Alan Wells & Herminio & Nedo Nadj & Cristina de Borbón & Pérec \\
\hline Alberto & Menéndez & Noureddine & Daniela Silivas & Marion Jones \\
\hline Juantorena & Iker Martínez & Morceli & Enriqueta Basilio & Marjorie \\
\hline Aldo Nadj & Imre Németh & Oscar Pistorius & Ethel Bleibtrey & Gestring \\
\hline Antón Geesink & James B. Conolly & Paavo Nurmi & Fanny Blankers- & Marlene Ottey \\
\hline Archie Hahn & Jason Lezak & Patrick Makau & Koen & Nadia Comaneci \\
\hline Armin Hari & Jesse Owens & Paul Bert & Florence Griffith & Nawal El \\
\hline Bart Conner & Jesús G. & Elvstrom & Gail Devers & Moutawakel \\
\hline Ben Johnson & Margaride & Rafael Nadal & Gemma Mengual & Olga Korbut \\
\hline Bob Beamon & Jim Hines & Rafer Johnson & Grete Waitz & Renate Stecher \\
\hline Bob Hayes & Jim Thorpe & Ralph Hill & Heidi Schüller & Ulrike Mayfarth \\
\hline Carl Lewis & Joan Llaneras & Ralph Metcalfe & Hendrika & Vania Gesheva \\
\hline Cassius Clay & John Stephen & Ray C. Ewry & Masternbroek & Vera Caslavska \\
\hline Clarence Linde & Akhwari & Ricardo Zamora & Isabel Fernández & Wilma Rudolph \\
\hline Crabbe & Johnny & Robert Bruce & Jean Benoit & Yelena \\
\hline Cornelius & Weismuller & Mathias & & Shushunova \\
\hline Johnson & Jordi Llopart & Santiago Amat & & \\
\hline Daley & Juan Carlos I & Sebastian Coe & & \\
\hline Thompson & Kelly Holmes & Spyridon Louis & & \\
\hline David Cal & Kenenisa Bekele & Steve Ovett & & \\
\hline David López & Lasse Viren & Steve Redgrave & & \\
\hline Zubero & Lauri Lehtinen & Usain Bolt & & \\
\hline Dick Fosbury & Luz Long & Vicente Loren & & \\
\hline Donovan Bailey & Magic Johnson & Victor Boin & & \\
\hline Dorando Pietri & Mark Spitz & Vitalo Scherbo & & \\
\hline Eddie Tolan & Mat Biondi & Vladimir Kuts & & \\
\hline El Gerrouj & Michael Gross & Vladimir & & \\
\hline Emil Zápotek & Michael Johnson & Salnikov & & \\
\hline Felipe VI & Michael Jordan & Xavier & & \\
\hline Fermín Cacho & Michael Phelps & Fernández & & \\
\hline Fred Lorz & Miguel Indurain & Yshinori Sakay & & \\
\hline George Poage & & & & \\
\hline
\end{tabular}

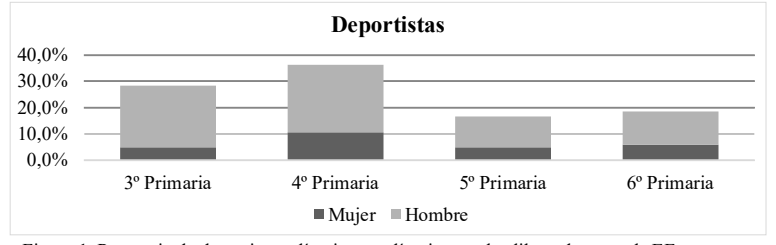

Figura 1. Presencia de deportistas olímpicos y olímpicas en los libros de texto de EF.

tipo de discapacidad.

El deporte olímpico practicado principalmente por las deportistas es el atletismo, con un $54.8 \%$, seguido de gimnasia con un $23.8 \%$ y la natación con un $11.9 \%$. En menor porcentaje se representa el piragüismo con un $4.8 \%$, y el judo y la vela con un $2.3 \%$.

En cuanto a la clasificación del deporte practicado por las referentes mencionadas destacan los deportes individuales, con un $66.67 \%$ de los casos. En cambio, en el $23.8 \%$ de los casos, las olímpicas han participado tanto en disciplinas individuales como de equipo; por último, el 9.52\% de las deportistas han participado únicamente en deportes colectivos.

Por otro lado, todas las olímpicas mencionadas en los libros de texto analizados han competido en los JJOO de verano, excluyendo de este modo a las deportistas que han participado en los JJOO de invierno o Paralímpicos.

Por último, destacar que la deportista olímpica mencionada en más ocasiones es Nadia Comaneci (exgimnasta rumana ganadora de nueves medallas olímpicas), con cuatro referencias. Le siguen las deportistas: Cathy Freeman, Fanny Blankers-Koen, Jean Benoit, Wilma Rudolph y Marie-José Pérec, con dos referencias. En cambio, las deportistas olímpicas españolas sólo se referencian en una ocasión de manera textual: Cristina de Borbón (vela), Isabel Fernández (judo) y María Vasco (atletismo), excepto Gemma Mengual (natación sincronizada) que aparece en imagen.

\section{Discusión}

Según los resultados encontrados respecto a la presencia y la recurrencia de las mujeres y los hombres deportistas en los libros de texto de EF en EP, son los hombres los que mayor presencia tienen en los manuales analizados. Esto coincide con el estudio de Sánchez et al. (2017), en donde las referencias deportivas femeninas olímpicas sólo aparecen en el $15 \%$ de la editorial Teide, omitiéndose en la editorial Serbal, en la etapa de Secundaria; y con el estudio de MoyaMata y Ros (2018), en el que la presencia femenina se reduce al 31.7\% de las imágenes, en la etapa de Primaria.

Además no existe prácticamente recurrencia, es decir, tanto los hombres como las mujeres deportistas aparecen en muy pocas ocasiones varias veces; al igual que en los estudios de Lopez-Navajas (2014) y Sánchez et al. (2017). Esta baja presencia y recurrencia de deportistas femeninas reducen las aportaciones y los logros de las mujeres al mundo deportivo olímpico. Aún siendo conscientes del auge actual del deporte olímpico femenino, tal y como muestran los porcentajes de participación femenina en los últimos eventos olímpicos; concretamente un $43 \%$ en las olimpiadas de invierno en Pionyang (2018), y un 45\% y $38.7 \%$ en las olimpiadas de verano y paraolimpiadas en Río de Janeiro (2016), respectivamente (IOC, 2018).

Diversos estudios constatan el desigual tratamiento dispensado al deporte femenino respecto al masculino en los medios de comunicación, tanto nacionales como internacionales, (Gómez-Colell, 2015; Gómez-Colell et al., 2017; Ibáñez, 2001; Sainz de Baranda, 2014); o el número de noticias deportivas femeninas, pero de manera estereotipada (Gallur, \& García, 2019). Igualmente, esta infrarrepresentación femenina frente a la masculina queda patente en los libros de texto de EF (González-Palomares et al., 2017; López-Navajas, 2014; Martínez-Bello, \& Molina-García, 2016; Moya-Mata et al., 2018; Moya-Mata, Ruiz-Sanchis et al., 2019; Moya-Mata, Ruiz, et al., 2017; Táboas-Pais, \& Rey-Cao, 2012a,b). Traduciéndose todo ello en la ausencia de referencias deportivas femeninas olímpicas para niñas, niños y adolescentes; ya que no cabe duda de que la escuela y los medios de comunicación son agentes importantes en el proceso de socialización.

Con respecto a los referentes deportivos mostrados en los manuales analizados en Primaria, al igual que en el estudio de Moya-Mata y Ros (2018), es de destacar que se ofrece un mayor número de referentes deportivos, que en la etapa de Secundaria (Sánchez et al., 2017). Concretamente, en este estudio se obtiene una presencia de 91 hombres y 35 mujeres en la editorial Edelvives; mientras que en el estudio de Sánchez et al. (2017), la editorial Teide muestra una presencia de 28 hombres y 5 mujeres, y la editorial Serbal sólo de cuatro hombres y ninguna mujer. Por lo que se puede afirmar que en los libros de texto EF de Primaria existe una mayor visibilización de la mujer deportista, que en la etapa de Secundaria. Siendo $4^{\circ}$ de EP, el curso donde más se visibiliza a las deportistas femeninas.

La nacionalidad más representada de estas deportistas es la estadounidense, lo que conlleva un trasfondo de currículum oculto, al transmitir en este caso ciertos estereotipos culturales, debido a la asociación de una determinada nacio- 
nalidad, a los éxitos deportivos femeninos. Aun así, la deportista más referenciada en los libros de texto analizados es la gimnasta Nadia Comaneci, siendo la rumana la tercera nacionalidad más representada junto a la española, representada por Cristina de Borbón, Gemma Mengual, Isabel Fernández y María Vasco. Se echa en falta más referentes de deportistas españolas, como por ejemplo, Rosa Torras y Lili Álvarez, precursoras ambas del deporte olímpico femenino español en los JJOO de París en 1924. Estos son únicamente dos ejemplos de las muchas deportistas españolas que podrían referenciarse en estos manuales, en virtud de los méritos deportivos logrados; sobre todo si se tiene en cuenta que los libros analizados fueron editados en el año 2013 y solo un año antes, en los JJOO celebrados en Londres (2012), de las 17 medallas conseguidas por la delegación española, 11 fueron de deportistas femeninas.

Entre todas las referentes femeninas seleccionadas en estos manuales, ninguna es deportista paralímpica. Por lo que una vez más se comprueba la doble discriminación que sufre la mujer con discapacidad: por su sexo y por su discapacidad (Moya-Mata, Ruiz, et al., 2017; Táboas-Pais, \& Rey-Cao, 2012b). Desaprovechándose la oportunidad de visibilizar a deportistas como por ejemplo: Trischa Zorn, nadadora estadounidense ganadora de 55 medallas; Teresa Perales, nadadora española con 26 medallas paralímpicas, de las cuales 22 fueron conseguidas en años anteriores a la publicación de los libros de texto analizados; o Santamarta Purificación, con 11 medallas de oro, que la sitúan como la deportista paralímpica con más victorias en los juegos en la historia del deporte paralímpico español. Por lo tanto, los libros de texto de EF españoles no fomentan el deporte español e invisibilizan los logros de las deportistas paralímpicas españolas; aun teniendo un convenio de colaboración con elCOE

Los deportes más representados en estos manuales por deportistas femeninas son los deportes individuales, y concretamente, el atletismo; tal y como confirman estudios precedentes en Primaria y Secundaria (González-Palomares et al., 2017; Moya-Mata, \& Ros, 2018; Moya-Mata et al., 2018; Sánchez et al., 2017). Así como en el análisis de la prensa deportiva de Gómez-Colell et al. (2017); aunque, difiere parcialmente con los resultados obtenidos en el estudio de Sainz de Baranda (2014), en el que el tenis es el deporte con más representación femenina, seguido del atletismo. Pero una vez más, se sigue asociando a la mujer con deportes individuales, en donde no hay contacto físico con otras deportistas. Desaprovechándose la oportunidad de visibilizar deportes colectivos, y por lo tanto, equipos femeninos como referentes para nuestro alumnado, como por ejemplo los equipos olímpicos de balonmano, waterpolo y natación sincronizado que consiguieron medalla olímpica en los JJOO de Londres en 2012. Ya que únicamente se representan en estos manuales seis de los 26 deportes oficiales que conformaron el programa olímpico de Londres (2012), última celebración olímpica celebrada con anterioridad a la publicación de los manuales de texto analizados.

Asimismo, llama la atención que a pesar del convenio de colaboración existente entre la editorial de los libros de texto analizados y el COE, mediante el cual se trata de difundir los valores olímpicos entre los escolares, no se haga referencia a deportistas que han participado en los JJOO de invierno, o en los JJPP; en donde encontramos también un gran número de referentes.

\section{Conclusiones}

El estudio realizado es un ejemplo más del escaso número de referentes de deportistas femeninas olímpicas en los libros de texto de EF en EP. Esta circunstancia se traduce en un escaso número de modelos deportivos femeninos para el alumnado de esta etapa educativa. Además, destaca las pocas referencias a deportistas españolas y la ausencia de participantes en los JJOO de invierno y JJPP, dado que esto contrasta con la idea de que en esta etapa educativa deben fomentarse valores que favorezcan la atención a la diversidad, la inclusión y la igualdad de oportunidades.

Por tanto, resulta necesaria la revisión de los materiales curriculares por parte de las editoriales, para aumentar la presencia de las mujeres olímpicas y ofrecer modelos femeninos que se alejen de los estereotipos de género, para que de este modo las niñas y los niños tengan también la posibilidad de escoger modelos deportivos femeninos con los que sentirse identificados y contribuir de este modo a alcanzar la igualdad de género en todos los ámbitos sociales. Mientras tanto, los y las docentes pueden utilizar este material en el aula de forma crítica, haciendo consciente al alumnado de la omisión de referentes y partícipe para solucionar esta gran omisión, desde un punto de vista multidisciplinar.

\section{Referencias}

Angulo, M. (2007). Las imágenes de las deportistas en los medios de comunicación. Madrid: Consejo Superior de Deportes.

ASPIC-Comunicación. (2013). Presencia y tratamiento del deporte femenino en la prensa generalista vasca y en periódicos de información deportiva. Vitoria-Gasteiz: Dirección de Juventud y Deportes.

Braga, G., \& Belver J.L. (2014). El análisis de libros de texto: una estrategia metodológica en la formación de los profesionales de la educación. Revista Complutense de Educación, 27(1), 199-217.

Chinurum, J., Ogunjlmi, L., \& O’Neill, C. (2014). Gender and Sport in Contemporary Society. Journal of Educational and Social Research, 4(7), 25-30. doi: 10.5901/ jesr.2014.v4n7p25

Gallur, S., \& García, B. (2019). La presencia de la mujer en las informaciones de los cibermedios europeos de España, Italia, Gran Bretaña, Portugal y Francia. Revista Latina de Comunicación Social, 74, 403-417. doi: 10.4185/RLCS2019-1337

Gómez-Colell, E. (2015). Adolescencia y deporte: ausencia de referentes femeninos en los medios para las adolescentes. Apunts. Educación Física y Deportes, 122, 81-87. doi: 10.5672/apunts.2014-0983.es.(2015/4).122.09

Gómez-Colell, E., Medina-Bravo, P., \& Ramón, X. (2017). La presencia invisible de la mujer deportista en la prensa deportiva española. Análisis de las portadas de «Marca», «As», «Mundo Deportivo»y «Sport» (2010-2015). Estudios sobre el Mensaje Periodístico, 23(2), 793-809. 
González-Palomares, A., Táboas-Pais, M.I., \& Rey-Cao, A. (2017). La cultura corporal en función del género: Análisis de los libros de texto de educación física de secundaria publicados durante la ley orgánica de educación. Educación XX1, 20(1), 142-162.

Ibáñez, E. (2001). Información sobre el deporte femenino: el gran olvido. Apunts. Educación Física y Deportes, 65(3), 111-113.

International Olympic Committee. (2018). Olympics, Olympic Games, Medals, Results, News. IOC. Recuperado de https:/www.olympic.org/

Jiménez, R. (2015). El deporte femenino español en los Juegos Olímpicos. Madrid: Consejo Superior de Deportes. Recuperado de http://transparencia.gob.es/transparencia/dam/jcr:7aa457c3-2ecc-4eff-aff7-286ae022fc65/ Deporte_Femenino_JJOO.pdf

La Vanguardia (2019). El Atlético-Barça femenino bate el récord de asistencia a un partido entre clubes. Recuperado de https://www.lavanguardia.com/deportes/fcbarcelona/20190317/461077968694/asistencia-recordwanda-metropolitano-atletico-barcelona.html

Ley Orgánica 8/2013, de 9 de diciembre, para la Mejora de la Calidad Educativa. BOE n ${ }^{\circ} 295$, de 10 de diciembre de 2013.

Lleixà, T., Soler, S., \& Serra, P. (2020). Perspectiva de género en la formación de maestras y maestros de Educación Física. Retos, 37. Pendiente de publicación.

López-Navajas, A. (2014). Análisis de la ausencia de las mujeres en los manuales de la ESO: una genealogía de conocimiento ocultada. Revista de Educación, 363, 282-308. doi: 10.4438/1988-592X-RE-2012-363-188

Martínez-Bello, V., \& Molina-García, J. (2016). Representation of physical activity domains and sedentary behaviours in physical education textbooks: an image analysis. South African Journal for Research in Sport, Physical Education and Recreation, 38(2), 139-152.

Meier, M. (2015). The value of female sporting role models. Sport in Society, Cultures, Commerce, Media, Politics. 18,968-982. doi: 10.1080/17430437.2014.997581

Moya-Mata, I., Ros, C., \& Peirats, J. (2018). ¿Qué representan las portadas de los libros de texto de Educación Física en Primaria? Retos, Nuevas tendencias en Educación Física, Deportes y Recreación, 34, 295-299.

Moya-Mata, I., Ruiz, L., Martín, J., Pérez, P., \& Ros, C. (2017).
La representación de la discapacidad en las imágenes de los libros de texto de Educación Física: ¿inclusión o exclusión? Retos. Nuevas tendencias en Educación Física, Deportes y Recreación, 32, 85-95.

Moya-Mata, I., Ruiz-Sanchis, L., Martín, J., \& Ros, C. (2019). Estereotipos de género en las imágenes que representan las actividades en el medio natural en los libros de Educación Física de Primaria. CCD. Cultura_Ciencia_Deporte,14(40), 15-23.doi: 10.12800/ ccd.v14i40.1222

Moya-Mata, I., Ruiz, L., \& Ros, C. (2017). Análisis de las portadas de los libros de texto de Educación Física en Primaria. Estudios pedagógicos, 43(1), 235-250. doi: 10.4067/S0718-07052017000100014

Moya-Mata, I., \& Ros, C. (2018). Modelos femeninos en el deporte a través de las imágenes en Primaria. En LópezMeneses, E.; Cobos-Sanchiz, D.; Martín-Padilla, A.H.; Molina-García, L.; Jaén-Martínez, A. Experiencias pedagógicas e innovación educativa. Aportaciones desde la praxis docente e investigadora (pp. 3879-3890). Barcelona, España: Octaedro Editorial.

Olmstead, M. (2015). What are the Benefits of Having Female Athletes as Role Models for Young Girls. Women's Sports Foundation. Recuperado de https:// www.womenssportsfoundation.org/education/what-arethe-benefits-of-having-female-athletes-as-role-modelsfor-young-girls/

Sainz de Baranda, C. (2014). Las mujeres en la prensa deportiva: dos perfiles. Cuadernos de Psicología Del Deporte, 14(1),91-102. doi:10.4321/S1578-84232014000100011.

Sánchez, N., Martos-García, D., \& López, A. (2017). Las mujeres en los materiales curriculares: el caso de dos libros de texto de Educación Física. Retos, Nuevas tendencias en Educación Física, Deportes y Recreación, 32, 140145.

Sesé, J.M. (2008). Los Juegos Olímpicos en la Antigüedad. Cultura, Ciencia y Deporte, 9, 201-211.

Táboas-Pais, M. ${ }^{a}$ I., \& Rey-Cao, A. (2012a). Gender Differences in Physical Education Textbooks in Spain: A Content Analysis of Photographs. Sex Roles, 67, 389402. doi: 10.1007/s11199-012-y

Táboas-Pais, Mª I., \& Rey-Cao, A. (2012b). Disability in physical education textbooks: an analysis of image content. Adapted Physical Activity Quarterly, 29(4), 310328.
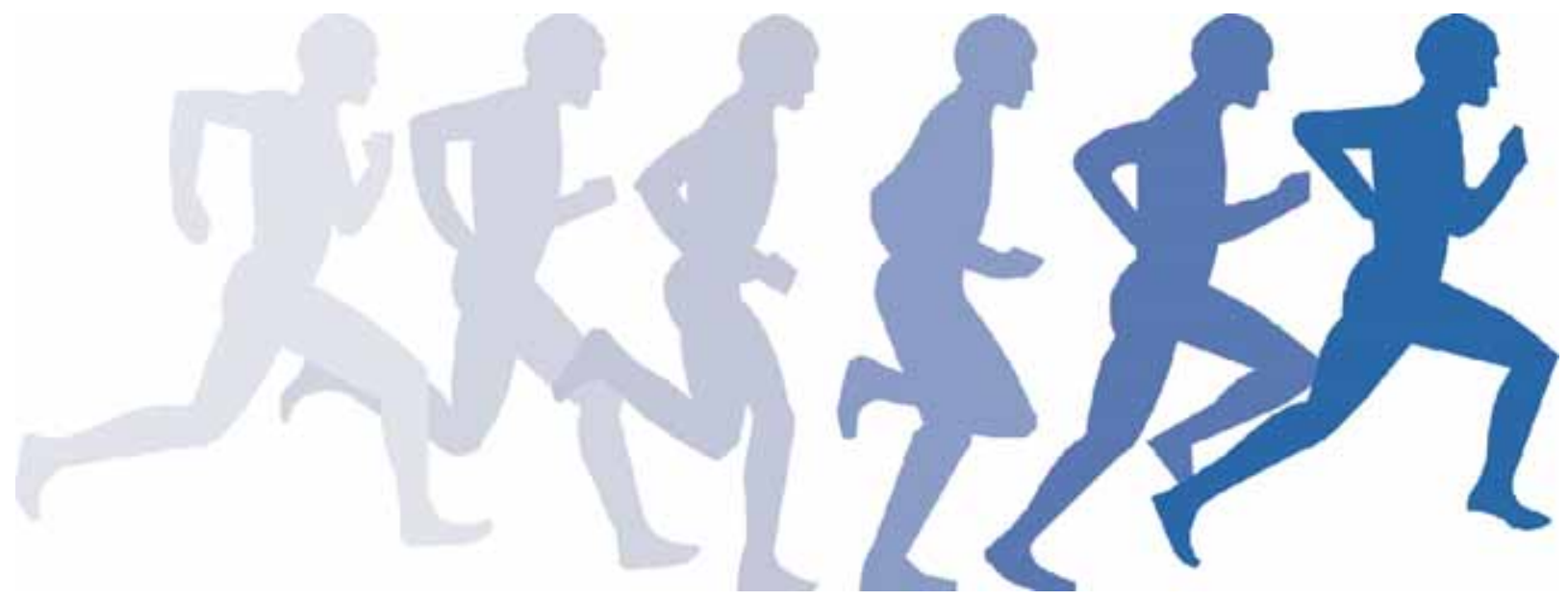